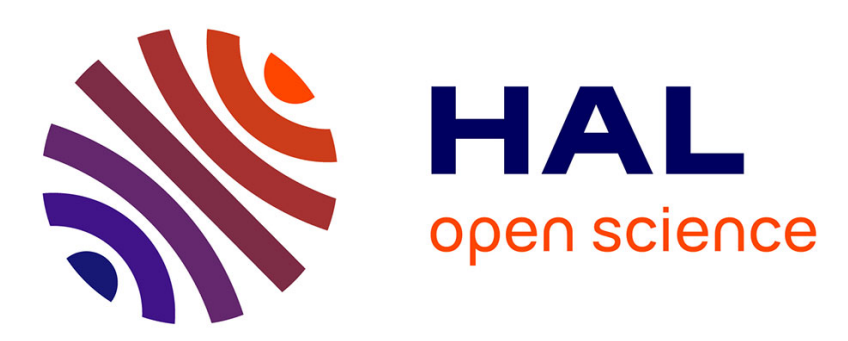

\title{
Diffusion coefficient in a semi-dilute solution measured by concentration gradient technique and compared to quasielastic light scattering results
}

M. Adam, M. Delsanti, G. Pouyet

\section{- To cite this version:}

M. Adam, M. Delsanti, G. Pouyet. Diffusion coefficient in a semi-dilute solution measured by concentration gradient technique and compared to quasielastic light scattering results. Journal de Physique Lettres, 1979, 40 (17), pp.435-438. 10.1051/jphyslet:019790040017043500 . jpa-00231660

\author{
HAL Id: jpa-00231660 \\ https://hal.science/jpa-00231660
}

Submitted on 1 Jan 1979

HAL is a multi-disciplinary open access archive for the deposit and dissemination of scientific research documents, whether they are published or not. The documents may come from teaching and research institutions in France or abroad, or from public or private research centers.
L'archive ouverte pluridisciplinaire HAL, est destinée au dépôt et à la diffusion de documents scientifiques de niveau recherche, publiés ou non, émanant des établissements d'enseignement et de recherche français ou étrangers, des laboratoires publics ou privés. 


\title{
Diffusion coefficient in a semi-dilute solution measured by concentration gradient technique and compared to quasielastic light scattering results
}

\author{
M. Adam, M. Delsanti and G. Pouyet (*) \\ DPh-G/PSRM, CEN. Saclay, B.P. No 2, 91190 Gif s/Yvette, France
}

(Reçu le 17 mai 1979, accepté le 4 juillet 1979)

\begin{abstract}
Résumé. - Nous montrons expérimentalement, que le coefficient de diffusion translationnel d'une solution semidiluée est indépendant de l'échelle de temps sur laquelle s'effectue la mesure.

Ceci impose que, dans ce cas, les compressibilités isotherme et adiabatique soient identiques, et l'on peut interpréter le coefficient de diffusion

- soit comme résultant d'un mouvement coopératif d'un pseudogel

- soit comme résultant du déplacement d'une chaîne sans interaction hydrodynamique entre ses éléments.

Abstract. - We show experimentally that the translational diffusion coefficient of a semi-dilute solution does not depend on the time scale over which the measurement is made.

As a consequence isothermal and adiabatic compressibilities are identical in semi-dilute solutions, and this diffusion coefficient can be viewed either as a cooperative diffusion coefficient in the pseudo-gel model, or as a diffusion coefficient of a coil without hydrodynamic interactions between its elements.
\end{abstract}

A semi-dilute solution is characterized by an interpenetration of the coils, when the monomer concentration $c$ is bigger than the overlap concentration $c^{*}[1]$ ( $c^{*}=M / R^{3}$, where $M$ is the mass and $R$ the radius of gyration of the coil). One can define an average distance $\xi$ between contact points which depends only on concentration $\left(\xi \sim c^{-0.75}\right)$.

One can also define an average life time $T_{\mathrm{R}}$ of the contact points which is identical to the time necessary for a semi-dilute coil to change its conformation [2] ; $T_{\mathrm{R}}$ is called the reptation time.

If one observes the relaxation properties of a semi-dilute solution resulting from a constraint such as a stress : a viscoelastic response is observed if the observation is made in a time interval smaller than $T_{R}$, whereas the response is purely viscous if the observation is made in an interval greater than $T_{\mathrm{R}}[3]$.

However, when the constraint is a concentration gradient we find that the relaxation process, i.e. the translational diffusion coefficient, is independent of the time interval.

(*) Centre de Recherche sur les Macromolécules, 67083 Strasbourg Cedex, France.
The diffusion coefficient is defined as the ratio of the rate of transfer of a diffusion substance, per unit area, to the concentration gradient.

It can be expressed as [4] :

$$
D \simeq \frac{M}{f} \frac{\partial \pi}{\partial c}
$$

where $f$ and $M$ are respectively the frictional coefficient and the mass of the moving species, and $\pi$ the osmotic pressure of the solution.

The diffusion coefficient in a time interval shorter than $T_{\mathrm{R}}$ has been calculated [1] as follows : the semidilute solution is considered as a gel of mesh size $\xi$, the diffusion coefficient is equal to the ratio [5]

$$
D \simeq \frac{E}{\varphi}
$$

where $E$ is the elastic modulus of the transient network, and $\varphi$ the friction of the solvent through one unit volume of gel. If $E$ and $\varphi$ are expressed as a function of $\xi$, the diffusion coefficient is found to be equal to [6]

$$
D \simeq \frac{k T}{f(\xi)}
$$


where $f(\xi)$ is the frictional coefficient of one element of size $\xi$ called a blob.

The semi-dilute solution can also be considered as a non interacting assembly of blobs, then

$$
D \simeq \frac{M(\xi)}{f(\xi)} \cdot \frac{\partial \pi}{\partial c} \simeq \frac{k T}{f(\xi)}
$$

$D$ is independent of molecular weight and scales with concentration as a power law.

The quasi-elastic light scattering technique has been widely used [7] in order to measure the diffusion coefficient at a time scale much shorter than $T_{\mathrm{R}}$. This technique allows us to determine the characteristic decay time $\tau$ of spontaneous concentration fluctuations on a space scale $k^{-1}$ ( $k$ is the transfer vector).

It has been found for the polystyrene benzene system, at room temperature that $\tau=\left(D k^{2}\right)^{-1}$ and $D=5.63 \times 10^{-6} c^{0.67} \mathrm{~cm}^{2} \mathrm{~s}^{-1}[8]$.

The characteristic time $\tau$

$$
\text { and }
$$$$
\tau=1.32 \times 10^{-4} \mathrm{~s} \text { for } k=10^{5} \mathrm{~cm}^{-1}
$$

$$
c=5 \times 10^{-2} \mathrm{~g} / \mathrm{g}
$$

is effectively much shorter than $T_{\mathrm{R}}$, whose calculated value (according [1]) is $T_{\mathrm{R}}=0.2 \mathrm{~s}$ for $M=3.8 \times 10^{6}$ and $c=5 \times 10^{-2} \mathrm{~g} / \mathrm{g}$.

In order to estimate the diffusion coefficient at a time scale longer than $T_{\mathrm{R}}$ we must observe the concentration relaxation from a finite concentration gradient. In this case, we have to assume that we observe either the displacement of the whole macromolecule towards a less concentrated region (a) or the swelling of the pseudo-gel (b).

a) A macromolecule, in a semi-dilute solution, is considered as made of $g$ blobs without hydrodynamic interactions. Its frictional coefficient is :

$$
f=g \cdot f(\xi) \text { where } g=\frac{M}{c \xi^{3}} .
$$

The osmotic pressure is :

$$
\pi \simeq \frac{k T}{\xi^{3}}
$$

and the diffusion coefficient using equation (1) is :

$$
D \simeq \frac{k T}{f(\xi)}
$$

as in the pseudo-gel model but to obtain this last result we had to assume that adiabatic and isothermal compressibilities are identical [9].

b) In order to be swollen by the solvent the transient network locally adjusts its mesh size. There is no macroscopic displacement of one semi-dilute coil. Such a situation has been studied by Tanaka et al. [10] in a polyacrylamide gel : they have proved that the diffusion coefficient could be measured either by light scattering or by the variation with time of the macroscopic radius of a small gel sphere being swollen by the solvent.

Thus, the diffusion coefficient should not depend on molecular weight and should vary with concentration as a power law, whatever the time scale.

In the concentration gradient technique the measurement of $D$ is made on a millimetre scale $l$ which corresponds to a time $t=D^{-1} l^{2}$ which is $10^{8}$ bigger than the time involved in a quasi-elastic light scattering experiment.

The step like concentration is obtained in a double sector capillary-type cell using an ultracentrifuge (Fig. 1), each cell compartment is filled with a semidilute solution with respective monomer concentrations $c_{1}$ and $c_{2}\left(c_{1}-c_{2} \approx 3 \times 10^{-3} \mathrm{~g} / \mathrm{g}\right)$. The synthetic boundary is due to centrifugal forces. The whole experiment was made at low speed in order to keep the sedimentation effects negligible compared to the diffusion process. The Beckman ultracentrifuge gives us the concentration gradient profile by the Schlieren technique. The diffusion coefficient is obtained by the height-area [11] method from photographs of the Schlieren pattern taken every four minutes. Since $c_{1}-c_{2}$ is very small $\left(3 \times 10^{-3} \mathrm{~g} / \mathrm{g}\right)$ we can neglect the dependence of the diffusion coefficient

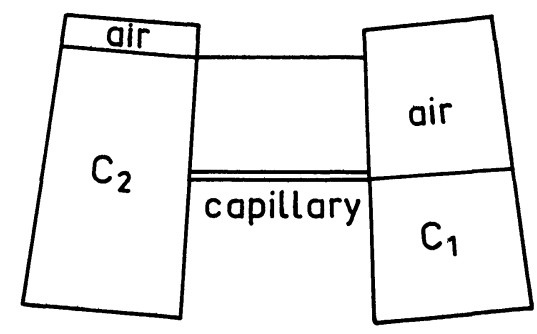

(a)

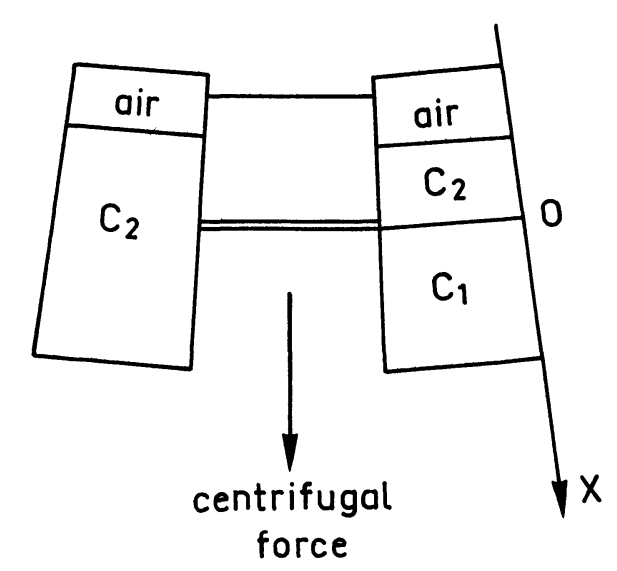

(b)

Fig. 1. - Schematic representation of the two compartment cell, a) before rotation, the dimension of the capillary does not allow $c_{2}$ to go to the $c_{1}$ compartment ; $b$ ) during the rotation, $c_{2}$ is now superposed to $c_{1}$, and the step like concentration gradient is produced. The $x$ axis and its origin are represented. 
on the concentration difference [12] and consider $D$ as a constant with respect to position $x$ and time $t$ ( $x=0$ is the boundary position between solutions $c_{1}$ and $c_{2}$ at the initial time $t=0$ ). At time $t$, the height of the gaussian-like concentration gradient is :

$$
\left(\frac{\partial c}{\partial x}\right)_{t, x=0}=\frac{c_{1}-c_{2}}{2(\pi D t)^{1 / 2}}
$$

and the integral of the concentration gradient is a constant equal to $c_{1}-c_{2}$.

Measuring the ratio $A$ of the surface to the height of the Schlieren pattern we obtain the diffusion coefficient (Fig. 2).

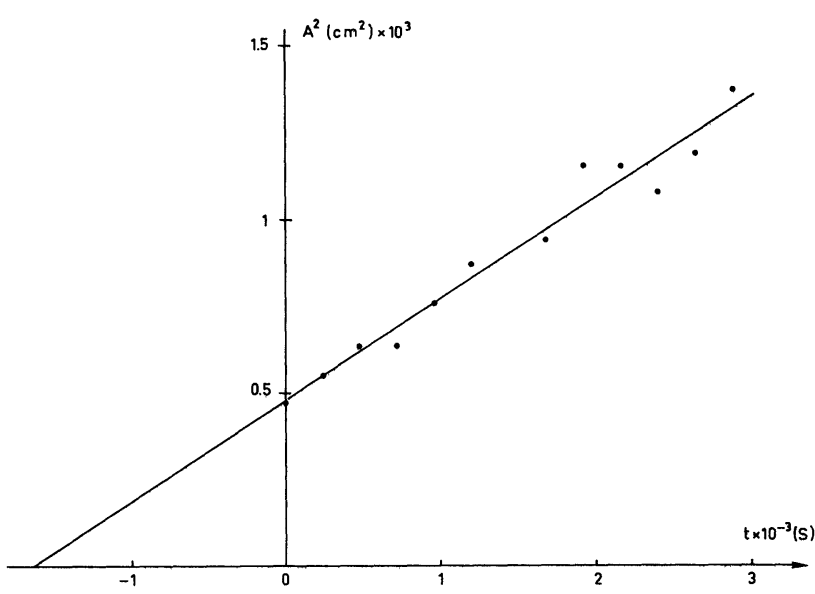

Fig. 2. - Variation of the square of the ratio $A$ of the surface to the height of the Schlieren pattern as a function of time. The intercept of the straight line with the time axis gives the initial time $t_{\mathrm{i}}$ of the diffusing process, the slope of this line gives the diffusion coefficient $D\left(D=2.95 \times 10^{-7} \mathrm{~cm}^{2} \mathrm{~s}^{-1}, 24^{\circ} \mathrm{C}\right)$ by the relation : $A^{2}=D\left(t-t_{\mathrm{i}}\right)$.

These experiments were performed on polystyrenebenzene solutions using three different molecular weights of narrow polydispersity, the sample characteristics and the measured $D$ values are listed in the table I. We find that the diffusion coefficient does not depend on the molecular weight, but does depend on concentration.

In figure 3 , we have compared the variation of the diffusion coefficient with concentration obtained by both methods : step like concentration gradient and light scattering.

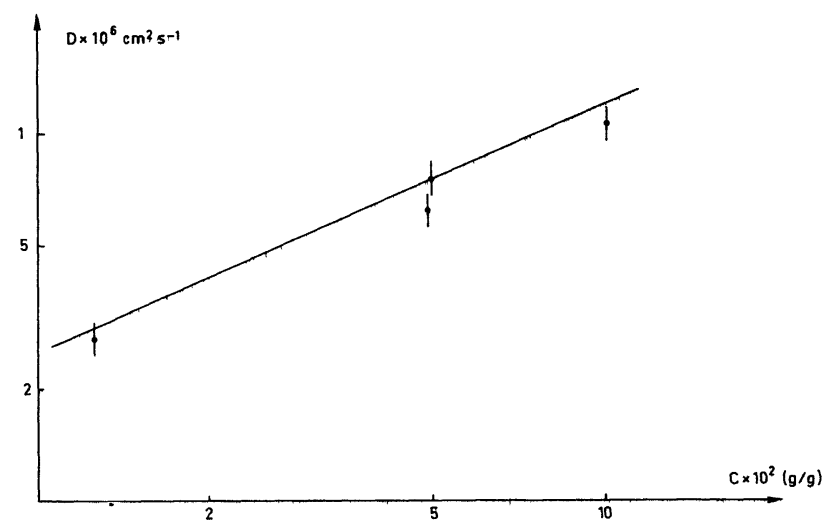

Fig. 3. - Variation of the diffusion coefficient with concentration, best fit obtained from quasi-elastic light scattering results; gradient concentration results $\left(c=\left(c_{1}+c_{2}\right) / 2\right)$.

Thus within experimental errors, the diffusion coefficient is independent of the time scale over which the measurements are performed.

With this experimental result we can show that the sedimentation coefficient $S=(M / f)$ is insensitive to the experimental time scale.

It can be shown that $S$ is related to the diffusion coefficient by $S=D \cdot(\partial \pi / \partial c)^{-1}$. The sedimentation coefficient as well as $D$ and $\partial \pi / \partial c$ are independent of the model $a$ or $b$ described above, it is non molecular weight dependent [13] in the semi-dilute range of concentrations.

Acknowledgments. - The authors gratefully thank H. Benoit and G. Weill for their advice in the choice of the experimental technique and J. P. Cotton, P. G de Gennes, G. Jannink and C. Williams for various discussions.

Table I. - Characteristic of the samples used and the measured diffusion coefficient values. $c$ is the mean concentration $\left(c=\left(c_{1}+c_{2}\right) / 2\right) . c^{*}$ in $\mathrm{g} / \mathrm{g}$ is calculated following the formula given in reference [7] (Adam-Delsanti).

$$
c^{*}=6.22 \times 10^{2} M^{-0.785}
$$

$\begin{array}{cccccc}M_{\mathrm{w}} & M_{\mathrm{w}} / M_{\mathrm{n}} & \begin{array}{c}c_{1}-c_{2} \\ (\mathrm{~g} / \mathrm{g})\end{array} & c(\mathrm{~g} / \mathrm{g}) & c / c^{*} & \begin{array}{c}D\left(\mathrm{~cm}^{2} \mathrm{~s}^{-1}\right) \text { standard } \\ \text { temperature } 20^{\circ} \mathrm{C}\end{array} \\ 5.8 \times 10^{6} & - & - & - & - & - \\ 6.3 \times 10^{5} & 1.18 & 1.1 \times 10^{-3} & 1.27 \times 10^{-2} & 4.2 & 2.78 \times 10^{-7} \\ 3.2 \times 10^{5} & 1.17 & 2.8 \times 10^{-3} & 4.93 \times 10^{-2} & 2.8 & 6.22 \times 10^{-7} \\ 3.2 \times 10^{5} & 1.05 & 3.2 \times 10^{-3} & 4.99 \times 10^{-2} & 1.7 & 7.56 \times 10^{-7} \\ 1.1 \times 10^{5}\left(^{+}\right) & 1.05 & 3.2 \times 10^{-3} & 10.10 \times 10^{-2} & 3.4 & 1.07 \times 10^{-6} \\ & - & - & 0.115 \mathrm{~g} / \mathrm{cm}^{3} & \approx 2 & 1.11 \times 10^{-6}\end{array}$

$\left({ }^{+}\right)$Gradient concentration data taken from reference [14] (PS/toluene), the diffusion has been corrected to the benzene viscosity at $20^{\circ} \mathrm{C}$. 


\section{References and Notes}

[1] DE Gennes, P. G., Macromolecules 9 (1976) 587-594.

[2] Daoud, M., De Gennes, P. G., to be published in J. Polym. Sci.

[3] Ferry, J., Viscoelastic properties of polymers (J. Wiley) 1970.

[4] See for instance : FLORY, P. J., Principles of Polymer Chemistry (Cornell University Press. Ithaca N.Y.) 1969, p. 305.

[5] TanaKa, T., Hocker, L. O., BenedeK, G. B., J. Chem. Phys. 59 (1973) 5151.

[6] If $A=$ constant $\times B$, and the constant is dimensionless, we will write $A \simeq B . A \sim B$ means $A$ proportional to $B$.

[7] Delsanti, M., Thesis, Paris (1978).

Adam, M., Delsanti, M., Macromolecules 10 (1977) 1229.

Munch, J. P., CANdau, S., Herz, J. and Hild, G., J. Physique 38 (1977) 971.

Geissler, E. and Hecht, A. M., J. Chem. Phys. 65 (1976) 103.

[8] In the theoretical equation $c$ is given in $\mathrm{g} / \mathrm{cm}^{3}$ and $M$ is the mass of the species in movement. In the experimental formula $c$ is given in $\mathrm{g} / \mathrm{g}$, and $M$ is the molecular weight of the species considered.
[9] Brochard, F. and DE Gennes, P. G., Macromolecules 10 (1977) 1157.

[10] Tanaka, T. and Flllmore, D. J., J. Chem. Phys. 70 (1979) 1214.

[11] TANDFORD, C., Physical Chemistry of Macromolecules (J. Wiley) 1961.

[12] This point has been verified by the symmetrical aspect of the concentration gradient. The $D$ values obtained using either a method taking into account a concentration dependence or the height area method are identical within experimental precision $(10 \%)$.

[13] Pouyet, G. and Dayantis, J., Macromolecules 12 (1979). DestoR, C. and RONDELEZ, F., submitted to publication in Polym. Lett.

[14] Roots, J., Nystrom, B., Sundelof, L. O. and Porsh. B., Polymer 20 (1979) 337. 